\title{
APPROXIMATE CALCULATION OF BASIC CHARACTERISTICS OF PLASMA AT THE AIR ELECTRIC EXPLOSION OF METAL CONDUCTOR
}

\begin{abstract}
Purpose. Obtaining approximate calculation correlations for determination of maximal values of temperature $T_{m}$, and pressures $P_{m}$ at a shock wave and speed $v_{m}$ distribution of a shock wave in the plasma products of air electric explosion (EE) of metall conductor under act of large impulsive current (LIC). Methodology. Theoretical bases of the electrical engineering, scientific and technical bases of electrophysics, thermal physics and electrophysics bases of powerful high-voltage impulse technique, related to the theory and practice of the phenomenon EE metallic explorer in gas environments under action of LIC. Results. New calculation correlations are got for approximate calculation in a local area of EE in atmospheric air of metallic explorer of maximal values of temperature $T_{m}$, pressures $P_{m}$ and speeds of $v_{m}$ of shock wave in "metallic plasma" appearing from an explosion under action of LIC of its conducting structure. It is set that numeral values of the sought after sizes of temperature $T_{m}$, pressures $P_{m}$ and speeds $v_{m}$ as it applies to air EE thin copper conductor under the action of LIC of the microsecond temporal range can arrive at a few ten of thousands of Kelvin, hundreds of technical atmospheres and thousands of meters in a second accordingly. It is shown that similar values of speed $v_{m}$ of shock wave in "metallic plasma" are comparable at speed of detonation wave in hard explosives. An accent is in this connection done on expedience of application air EE thin short metallic conductors at injury of live ammunitions with an ordinary and nuclear explosive. The real technical suggestions are offered on a possible receipt in the discharge circuit of powerful high-voltage generator of LIC of condenser type of "record" (most) values of the examined descriptions of "metallic plasma" at air EE thin metallic conductors. Comparison of the obtained results is executed for the probed descriptions of plasma at air EE of the metal conductor with known in the world information in area of electrophysics and thermal physics EE metal in gas environments. Originality. The obtained new theoretical results in area of high-current electrophysics and high-temperature thermal physics extend our physical views about the phenomenon of EE in atmospheric air of thin metallic conductors under action of LIC of the nanosecond and microsecond duration. Practical value. Application of the calculation correlations obtained in practice for the indicated descriptions of "metallic plasma" will allow technicians-and-engineers in a certain measure to accelerate and improve adjusting of difficult electric charts of powerful high-voltage generator of LIC at a receipt in his discharge circuit by air EE of thin metal conductors required on protocol of lead through of heavy-current electrophysics experiments of parameters of plasma in the local zone of its explosion. References 14.

Key words: powerful high-voltage generator of current pulses of condenser type, metallic conductor, high pulse current, electric explosion of conductor, plasma, temperature, pressure, speed of distribution of shock wave in the plasma products of explosion, calculation.
\end{abstract}

Приведены результаты приближенного расчета максимальных значений температуры $T_{m}$, давления $P_{m}$ и скорости $v_{m}$ распространения ударной волны в «металлической плазме», образующейся при воздушном электрическом взрыве (ЭВ) тонкого металлического проводника под воздействием большого импульсного тока (БИТ). Показано, что при ЭВ в атмосферном воздухе тонкого медного проводника в разрядной цепи высоковольтного генератора БИТ микросекундного временного диапазона максимальные значения температуры $T_{m}$, давления $P_{m} и$ скорости $v_{m}$ в локальной зоне ее взрыва могут достигать соответственно нескольких десятков тысяч градусов кельвина, сотен технических атмосфер и тысяч метров в секунду. Сформулированы возможсные пути получения в разрядной цепи мощной конденсаторной батареи высоковольтного генератора БИТ «рекордных» значений температуры Т давления $\boldsymbol{P}_{\boldsymbol{m}}$ и скорости $\boldsymbol{v}_{\boldsymbol{m}}$. Библ. 14.

Ключевые слова: мощный высоковольтный генератор импульсов тока конденсаторного типа, металлический проводник, большой импульсный ток, электрический взрыв проводника, плазма, температура, давление, скорость распространения ударной волны в плазменных продуктах взрыва, расчет.

Introduction. The electric explosion (EE) of thin metal conductors in vacuum, gas and liquid media under the influence of a high pulsed current (HPC) flowing through them is currently widely used [1-9]: in experimental physics in the study of plasma; in nuclear engineering when creating local high-pressure zones; in high-voltage pulse technology (HVPT) in tests for the lightning strength of external and internal insulation of electric power equipment; in the HPC technique when creating fast circuit breakers of high-current circuits; in the technique of powerful pulsed light sources; in electrotechnologies in the production of micro- and nanopowders for the production of new composite materials; in electric discharge technologies for impact treatment of liquids and solids. The undesirable manifestation of EE of metal can be observed in the field of HVPT and HPC technique and with an unreasonable choice of the cross-sections of current-carrying parts of high-voltage high-current circuits of the corresponding equipment. Engineering personnel who carry out EE of thin metal conductors, usually in air and industrial water $[4,6]$ when debugging the required operating modes of used HVPT and predicting the devastating consequences 
for HVPT from the possible EE of its metallic conductors, simplified and convenient in practical applying approximate relationships for the operative calculation of the maximum levels of the temperature $T_{m}$, the pressure $P_{m}$, and the velocity $v_{m}$ of the propagation of the shock wave in the plasma products («metallic plasma»). However, as analysis of literary sources shows, insufficient attention is paid to obtaining such calculated ratios in the world. In this connection, obtaining approximate relations for the estimated quantitative determination of these parameters $T_{m}, P_{m}$ and $v_{m}$ is an actual applied scientific and technical problem both in the field of electrophysics and thermal physics.

The goal of the paper is obtaining approximate calculated relations for determining the maximum values of the temperature $T_{m}$, the pressure $P_{m}$ in the shock wave, and the velocity $v_{m}$ of propagation of the shock wave in the plasma products of the air electric explosion of a metallic conductor under the influence of a large pulse current.

1. Problem definition. Let us consider a thin metallic conductor of rectangular or cylindrical geometric shape located in the air under normal atmospheric conditions, along which HPC flows in its longitudinal direction from a high-voltage pulse energy source (for example, from a powerful charged lowinductance capacitor bank), whose amplitude-temporal parameters (ATPs) are sufficient to achieve in a conductive structure a conductor with a rectangular or circular cross section $S_{0}$ of the numerical value of the integral $J_{k}$ a current, which is critical for the test conductor. By the current integral $J_{k}$ we mean an integral defined in time $t$ by an expression of the form

$J_{k}=\int_{0}^{t_{k}} \delta_{k}^{2}(t) d t$, where $\delta_{k}(t)$ is the critical density of a

pulsed current in a conducting material of a conductor; $t_{k}$ is the time of the $\mathrm{EE}$ of the conductor [3-6]. For definiteness, we note that for a copper conductor in air at room temperature $20{ }^{\circ} \mathrm{C}$, the critical value of the indicated current integral $J_{k}$ is numerically about $11.95 \cdot 10^{17} \mathrm{~A}^{2} \cdot \mathrm{s} \cdot \mathrm{m}^{-4}[3]$. In addition, it should be borne in mind that for EE of metallic conductors, «fast» HPC generators are commonly used whose ATPs change in time according to the law of a damped sinusoid $[6,8]$. When a critical value of the current integral $J_{k}$ is reached in the conductor, the conducting structure of the latter will be subjected to an EE accompanied by rapid evaporation and sublimation of its material [3-6]. We assume that the density $\delta_{k}(t)$ of the pulse current has a uniform distribution along the cross section of the conductor under consideration [4]. We assume that at the initial stage of the $\mathrm{EE}$ of the thin conductor, the maximum values of the temperature $T_{m}$ and the pressure $P_{m}$ of the «metallic plasma» are uniformly distributed over the cross section of the sublimated material of the conductor, which is still within its section $S_{0}[3,4]$. We assume that the temperature $T_{m}$ is determined by the electron plasma temperature, which, in turn, is determined by the heat flow density $g_{m}$ in the conductor cross-section $S_{0}$. The initial air surrounding the conductor before its EE and the «metallic plasma» formed in place of the solid body of the conductor under study are assumed to be ideal gas media that satisfy the classical concept of an «ideal gas» with its limited volume [10]. Taking into account the normal atmospheric conditions to the EE of the conductor, the following basic characteristics for the initial air can be used [10]: the air pressure is $P_{1} \approx 1.013 \cdot 10^{5} \mathrm{~Pa}$; the air temperature was equal to $T_{1} \approx 273.15 \mathrm{~K}$; the molar volume of air is $V_{M 1} \approx 22.41 \cdot 10^{-3} \mathrm{~m}^{3} / \mathrm{mol}$. We confine ourselves to a quasi-static adiabatic process in the local zone around an electrically exploding metal of a conductor with a HPC flowing along it, in which there will be no heat exchange processes with the surrounding volume of the conductor with air surrounding the conductor [3, 4]. Taking into account the assumed assumptions, it is necessary to obtain approximate relations for the engineering estimation of the maximum values of the temperature $T_{m}$, the pressure $P_{m}$, and the velocity $v_{m}$ of the propagation of the shock wave in the plasma products of air EE of the metallic conductor under the influence of HPC.

2. Calculated estimation of the maximum temperature $T_{m}$ in the «metallic plasma» at the air EE of the conductor. Applying the Stefan-Boltzmann law to the plasma under consideration [10], for its temperature $T_{m}$ we write the following calculated relation:

$$
T_{m} \approx\left(\pi \sigma_{c}^{-1} g_{m}\right)^{1 / 4},
$$

where $\sigma_{c}=5.67 \cdot 10^{-8} \mathrm{~W} \cdot\left(\mathrm{m}^{2} \cdot \mathrm{K}^{4}\right)^{-1}$ is the Stefan-Boltzmann constant which characterizes the equilibrium thermal radiation of the «metallic plasma» in the EE region.

To find the value of the greatest heat flux density $g_{m}$ in the «metallic plasma» formed from the EE of the conductor, we use the following electrophysical relation [11]:

$$
g_{m} \approx \delta_{m k} U_{e},
$$

where $\delta_{m k} \approx I_{m k} / S_{0}$ is the amplitude of the critical current density in a conductor at its EE; $I_{m k}$ is the amplitude of the current flowing through the conductor at the time of its $\mathrm{EE} ; U_{e}$ is the near-electrode voltage drop in the edge zones of a sublimated conductor numerically not exceeding $10 \mathrm{~V}$ [12] for its basic metals used in HVPT and HPC technique.

In (2), the amplitude of the impulse current $I_{m k}$ in the high-current discharge circuit of the high-voltage HPC generator with the conductor under investigation can be found from the following approximate expression [8]:

$$
I_{m k} \approx\left(2 J_{k} S_{0}^{2} I_{m} \omega\right)^{1 / 3},
$$

where $I_{m}$ is the amplitude of the discharge current in the electrical circuit of the HPC generator, which varies with time $t$ with a circular frequency $\omega$ determined by the 
electrical parameters of the discharge circuit of the generator.

Then, from (1) - (3), for the maximum temperature $\mathrm{Tm}$ in the «metallic plasma» for air EE of a thin metal conductor under the influence of the HPC flowing through it in the final form, we obtain the following approximate relation:

$$
T_{m} \approx\left[\pi \sigma_{c}^{-1} U_{e}\left(2 J_{k} S_{0}^{-1} I_{m} \omega\right)^{1 / 3}\right]^{1 / 4} .
$$

It follows from (4) that in order to obtain the «record» (largest) temperatures $T_{m}$ in the «metallic plasma» formed in the air EE of the conductor due to the action of the HPC on it, the conductor material should be chosen with the largest values of $J_{k}$ and $U_{e}$, the crosssection $S_{0}$ the conductor is required to be taken as the smallest, while the amplitude $I_{m}$ and the circular frequency $\omega$ (the rate of increase) of the pulsed current in the discharge circuit of the HPC generator are the largest. That is why, in order to achieve high $T_{m}$ temperatures, it is advisable to use HPC generators with low-inductance and low-resistance discharge circuits and short thin electrically exploding conductors through which a pulse exponentially decaying sinusoidal current of nanosecond time range occurs.

The calculated estimation from (4) of the numerical value of the temperature $T_{m}$ of the «metallic plasma» for the experimental case of air EE of a thin circular copper conductor of radius $r_{0} \approx 0.1 \mathrm{~mm}$ and length $l_{0} \approx 110 \mathrm{~mm}$ under the influence of the HPC of the microsecond time range described in [8] $\left(J_{k} \approx 1.95 \cdot 10^{17} \mathrm{~A}^{2} \cdot \mathrm{s} \cdot \mathrm{m}^{-4} ; U_{e} \approx 10 \mathrm{~V}\right.$; $S_{0} \approx 3.14 \cdot 10^{-8} \mathrm{~m}^{2} ; I_{m} \approx 190 \mathrm{kA} ; \omega \approx 26.18 \cdot 10^{3} \mathrm{~s}^{-1}$ ) shows that in the considered approximation it will be approximately equal to $92.67 \cdot 10^{3} \mathrm{~K}$. To compare this calculated temperature $T_{m}$ of the "metallic plasma» with the worldknown data in the field of thermal physics of the EE of a metal, we indicate, according to the results of theoretical studies given in [13], the maximum explosion temperature in a vacuum of a lithium conductor $\left(2 r_{0} \approx 0.127 \mathrm{~mm}\right.$, $l_{0} \approx 10 \mathrm{~mm}$ ) included in the discharge circuit of a highvoltage HPC generator with the stored in its capacitors electric energy in it $100 \mathrm{~kJ}$, at the time of introduction of thermal energy into the conductor of $200 \mathrm{~ns}$, reached a numerical value of about $113.54 \cdot 10^{3} \mathrm{~K}$.

It should be pointed out that in [3] the experimental numerical values of the critical current integral $J_{k}$ are given, only for aluminum and copper conductors. In [14], data were presented for calculating the value of $J_{k}$ for other conductive materials used in HVPT and HPC technique for $\mathrm{EE}$ of thin metals when the current density $\delta_{k}$ in them is not less than $10^{10} \mathrm{~A} / \mathrm{m}^{2}$.

3. Calculated estimation of the maximum pressure $\boldsymbol{P}_{\boldsymbol{m}}$ in the «metallic plasma» at the air EE of the conductor. Taking into account the assumed assumptions and the equation of state of an ideal gas corresponding to the Clapeyron-Mendeleyev equation [10], for one mole of the air medium surrounding the metal conductor under investigation before the HPC is exposed to it and one mole of the «metallic plasma» in the air after the air EE of the conductor under consideration, write the following gas equation:

$$
P_{1} V_{M 1} / T_{1}=P_{m} V_{M 2} / T_{m}=R,
$$

where $R=8.314 \mathrm{~J} /(\mathrm{K} \cdot \mathrm{mol})$ is the universal gas constant [10]; $V_{M 2}$ is the molar volume of plasma products in the local zone of EE in the air of the conductor being studied, caused by the action of the HPC on it.

To determine $V_{M 2}$ in (5), we use the following approximate relation [10]:

$$
V_{M 2} \approx\left(M_{1}+M_{2}\right) / d_{2},
$$

where $M_{1}, M_{2}$ are, respectively, the molar mass of the initial air and the «metal plasma» formed in it in the local zone of the air EE of the metallic conductor; $d_{2}$ is the density of plasma products formed in the air local area after the EE of the conductor under the influence of HPC.

For the density $d_{2}$ of plasma products after the air $\mathrm{EE}$ of the metallic conductor, in the first approximation, we use a relationship of the form:

$$
d_{2} / d_{1} \approx\left(M_{1}+M_{2}\right) / M_{1},
$$

where $d \approx 1.293 \mathrm{~kg} / \mathrm{m}^{3}$ is the density of the received initial air surrounding the conductor before its EE [10].

According to (7), at the air EE of copper conductor $\left(M_{1} \approx d_{1} \cdot V_{M 1} \approx 28.97 \cdot 10^{-3} \mathrm{~kg} / \mathrm{mol} ; M_{2} \approx 63.55 \cdot 10^{-3} \mathrm{~kg} / \mathrm{mol}\right.$ [10]) it follows that $d_{2} \approx 4.129 \mathrm{~kg} / \mathrm{m}^{3}$. It can be seen that in this case the plasma products from the explosion of copper are only about 3.2 times denser than the initial air.

From (6) and (7) for the molar volume $V_{M 2}$ of plasma products after $\mathrm{EE}$ in the air of a metallic conductor, in the approximation obtained we obtain:

$$
V_{M 2} \approx M_{1} / d_{1} \approx V_{M 1} \approx 22.41 \cdot 10^{-3} \mathrm{~m}^{3} / \mathrm{mol} \text {. }
$$

Taking into account (8), from (5) for the required pressure $P_{m}$ in the «metallic plasma» we find:

$$
P_{m}=P_{1} T_{m} / T_{1}
$$

After substituting (4) into (9) for the maximum shock wave pressure $P_{m}$ in the local EE zone in the air of the metallic conductor caused by the action on its conductive material of HPC, we have:

$$
P_{m} \approx P_{1} T_{1}^{-1}\left[\pi \sigma_{c}^{-1} U_{e}\left(2 J_{k} S_{0}^{-1} I_{m} \omega\right)^{1 / 3}\right]^{1 / 4} .
$$

From (10) for the described above in Section 2 case of EE in air $\left(P_{1} \approx 1.013 \cdot 10^{5} \mathrm{~Pa} ; T_{1} \approx 27315 \mathrm{~K}\right)$ of the thin copper conductor with the microsecond HPC $\left(r_{0} \approx 0.1 \mathrm{~mm}\right.$; $l_{0} \approx 110 \mathrm{~mm} ; S_{0} \approx 3.14 \cdot 10^{-8} \mathrm{~m}^{2} ; \sigma_{c}=5.67 \cdot 10^{-8} \mathrm{~W} \cdot\left(\mathrm{m}^{2} \cdot \mathrm{K}^{4}\right)^{-1}$; $\left.J_{k} \approx 1.95 \cdot 10^{17} \mathrm{~A}^{2} \cdot \mathrm{s} \cdot \mathrm{m}^{-4} ; U_{e} \approx 10 \mathrm{~V} ; I_{m} \approx 190 \mathrm{kA} ; \omega \approx 26.18 \cdot 10^{3} \mathrm{~s}^{-1}\right)$ it follows that in this case a shock gas-dynamic pressure of up to $P_{m} \approx 343.7 \cdot 10^{5} \mathrm{~Pa}$ (up to $339.3 \mathrm{~atm}$ ) will appear in the local zone of its explosion. According to (9) and (10), in order to obtain the largest values of the shock pressure $P_{m}$ in the local air EE zone of the metallic conductor, it is necessary to create «record» levels of the absolute temperature $T_{m}$ of the «metallic plasma» in this zone (this zone). For this purpose it is required to use the smallest cross sections $S_{0}$ of short conductors, as well as «fast» 
HPC generators reproducing the largest amplitudes $I_{m}$ and the circular frequencies $\omega$ of their discharge current.

4. Calculation estimation of the maximum velocity $v_{m}$ of a shock wave in the «metallic plasma» at the air EV of the conductor. In the analyzed electrophysical case, the expression for the maximum velocity $v_{m}$ of propagation of the shock wave in the plasma products of the air EE of the metallic conductor can be represented in the form [10]:

$$
v_{m} \approx\left(\gamma_{a} R T_{m}\right)^{1 / 2},
$$

where $\gamma_{a}$ is the dimensionless adiabatic index.

Taking into account (4), the approximate relation (11) for the maximum velocity $v_{m}$ of the shock longitudinal wave in the «metallic plasma» from the EE in the air of the conductor takes the following final form:

$$
v_{m} \approx\left(\gamma_{a} R\right)^{1 / 2}\left[\pi \sigma_{c}^{-1} U_{e}\left(2 J_{k} S_{0}^{-1} I_{m} \omega\right)^{1 / 3}\right]^{1 / 8} .
$$

As for the numerical value in (11) and (12) of the dimensionless adiabatic index $\gamma_{a}$, for the equilibrium heatradiating system «high-current plasma discharge channelair» it is approximately equal to $\gamma_{a} \approx 4 / 3$ [10]. Then for the case of the air EE of the thin copper conductor used in [8] $\left(r_{0} \approx 0.1 \mathrm{~mm} ; l_{0} \approx 110 \mathrm{~mm} ; S_{0} \approx 3.14 \cdot 10^{-8} \mathrm{~m}^{2} ; U_{e} \approx 10 \mathrm{~V}\right.$; $\left.J_{k} \approx 1.95 \cdot 10^{17} \mathrm{~A}^{2} \cdot \mathrm{s} \cdot \mathrm{m}^{-4} ; \sigma_{c}=5.67 \cdot 10^{-8} \mathrm{~W} \cdot\left(\mathrm{m}^{2} \cdot \mathrm{K}^{4}\right)^{-1}\right)$ in the discharge circuit of the high-voltage generator of microsecond HPC $\left(I_{m} \approx 190 \mathrm{kA} ; \omega \approx 26.18 \cdot 10^{3} \mathrm{~s}^{-1}\right)$ from (12) we find that the maximum velocity $v_{m}$ of the shock wave in the plasma explosion products reaches a numerical value of about $4020 \mathrm{~m} / \mathrm{s}$. With the calculated estimations by (11), (12) for the maximum values of $v_{m}$, it should be remembered that by modulus $1 \mathrm{~mol}$, for example, for copper, according to the laws of molecular physics, is numerically $63.55 \cdot 10^{-3} \mathrm{~kg}$ [10] (remember that the dimension of the mole enters the universal gas constant $R$ ). Non-observance of the rules of the theory of dimensions in the practical application of the calculated relations (11) or (12) can lead to incorrect quantitative results for the sought value of the velocity $v_{m}$. The estimated numerical value of the maximum velocity $v_{m} \approx 4020 \mathrm{~m} / \mathrm{s}$ of the gas-dynamic shock wave in the «metallic plasma» obtained according to (12) corresponds to the velocity of the detonation wave in «slow» solid explosives $[9,10]$. In this connection, from the point of view of the possible attainment of these high velocities $v_{m}$ of the shock wave in plasma products of EE of metal, it seems expedient to use the air EE of thin metal conductors in high-efficiency electric detonators.

It follows from (12) that in order to obtain the «record» values of the velocity $v_{m}$ of a shock wave in the «metallic plasma» at the EV in the air of the conductors under consideration, it is necessary to use the minimum possible cross-sections $S_{0}$ of short metal conductors, as well as the maximum possible values for the high-voltage HPC generator of the amplitude $I_{m}$ and the circular frequency $\omega$ (the rate of increase) of its pulse discharge current which varies in time $t$ according to the law of a damped sinusoid.

\section{Conclusions.}

1. New relations (4), (10) and (12) are obtained for the engineering calculation, respectively, of the maximum values of the absolute temperature $T_{m}$, the shock pressure $P_{m}$ and the velocity $v_{m}$ of the propagation of the shock wave in the «metallic plasma», formed from the air EE of the metallic conductor under the action of the flowing on it HPC.

2. It is shown that for the $\mathrm{EE}$ in the air of thin metallic conductors connected in the discharge circuit of the high-voltage generator of HPC of the microsecond time range, the maximum calculated values of the temperature $T_{m}$, pressure $P_{m}$ and velocity $v_{m}$ can reach numerical values of several tens of thousands Kelvin, hundreds of technical atmospheres and thousands of meters per second.

3. On the basis of the calculated relationships (4), (10) and (12), real technical proposals for obtaining with the help of the EV in atmospheric air of thin metal conductors «record» (largest) values of the temperature $T_{m}$, the pressure $P_{m}$ and the shock wave velocity $v_{m}$ in the local zone of their explosion under the influence of HPC.

4. The new theoretical results obtained for certain assumptions for the required values of the temperature $T_{m}$, the pressure $P_{m}$, and the velocity $v_{m}$ allow us to deepen our physical representations in the field of high-current electrophysics and high-temperature thermal physics for the phenomenon of air EE of a thin metal conductor under the influence of the HPC of nano- and microsecond duration.

5. Taking into account the high calculated values of the velocity $v_{m}$ of the shock wave in the «metallic plasma», it can be concluded that the practical application of air EE of thin short metal conductors in high-efficiency electric detonators is advisable.

\section{REFERENCES}

1. Mesiats G.A. Impul'snaia energetika i elektronika [Pulsed power and electronics]. Moscow, Nauka Publ., 2004. 704 p. (Rus).

2. Dashuk P.N., Zayents S.L., Komel'kov V.S., Kuchinskiy G.S., Nikolaevskaya N.N., Shkuropat P.I., Shneerson G.A. Tehnika bol'shih impul'snyh tokov i magnitnyh polej [Technique large pulsed currents and magnetic fields]. Moscow, Atomizdat Publ., 1970. 472 p. (Rus).

3. Knopfel' G. Sverkhsil'nye impul'snye magnitnye polia [Ultra strong pulsed magnetic fields]. Moscow, Mir Publ., 1972. 391 p. (Rus).

4. Stolovich N.N. Elektrovzryvnye preobrazovateli energii [Electroexplosion energy converters]. Minsk, Nauka \& Tehnika Publ., 1983. 151 p. (Rus).

5. Burtsev V.A., Kalinin N.V., Luchynskiy A.V. Elektricheskiy vzryv provodnikov $i$ ego primenenie $v$ elektrofizicheskikh ustanovkakh [Electric explosion of conductors and its application in electrophysical options]. Moscow, Energoatomisdat Publ., 1990. 288 p. (Rus).

6. Gulyi G.A. Nauchnye osnovy razriadno-impul'snykh tekhnologii [Scientific basis of the discharge-pulse technology]. Kiev, Naukova Dumka Publ., 1990. 208 p. (Rus). 
7. Lerner M.I. Formation of nano-sizes phase at the electric explosion of explorers. Russian Physics Journal, 2006, vol.49, no.6, pp. 91-95.

8. Baranov M.I., Lysenko V.O. The main characteristics of an electric explosion of a metallic conductor at high impulse currents. Electricity, 2013, no.4, pp.24-30. (Rus).

9. Baranov M.I. An anthology of the distinguished achievements in science and technique. Part 40: The scientific opening of the method of explosive implosion for the obtaining above critical mass of nuclear charge and Ukrainian «track» in the «Manhattan» American atomic project. Electrical engineering \& electromechanics, 2017, no.5, pp. 3-13. doi: 10.20998/2074-272X.2017.5.01.

10. Kuz'michev V.E. Zakony i formuly fiziki [Laws and formulas of physics]. Kiev, Naukova Dumka Publ., 1989. 864 p. (Rus).

11. Baranov M.I. Izbrannye voprosy elektrofiziki: Monografija $v$ 2-h tomah. Tom 2, Kn. 1: Teorija elektrofizicheskih effektov $i$ zadach [Selected topics of Electrophysics: Monograph in 2 vols. Vol. 2, book. 1: Theory of electrophysics effects and tasks]. Kharkov, NTU «KhPI» Publ., 2009. 384 p. (Rus).

12. Raiser Yu.P. Fizika gazovogo razryada [Physics of gas discharge]. Moscow, Nauka Publ., 1987. 592 p. (Rus).

13. Rose K. Maksimal'naya temperatura vzryva provolochek $v$ vakuume / V kn. per. s angl.: Elektricheskiy vzryv provodnikov [The maximum temperature of a wire explosion in a vacuum / In book trans. with English: Electric explosion of conductors]. Moscow, Mir Publ., 1965, pp. 43-46. (Rus).

14. Baranov M.I. Analytical calculation of critical values of integral of current for parent metals, applied in the technique of large impulsive currents at the electric explosion of explorers. Technical Electrodynamics, 2008, no.6, pp. 14-17. (Rus).

Received 11.09.2017

M.I. Baranov ${ }^{1}$, Doctor of Technical Science, Chief Researcher, S.V. Rudakov ${ }^{2}$, Candidate of Technical Science, Associate Professor,

${ }^{1}$ Scientific-\&-Research Planning-\&-Design Institute «Molniya», National Technical University «Kharkiv Polytechnic Institute», 47, Shevchenko Str., Kharkiv, 61013, Ukraine, phone +380 577076841 ,

e-mail: baranovmi@kpi.kharkov.ua

${ }^{2}$ National University of Civil Protection of Ukraine, 94, Chernyshevska Str., Kharkiv, 61023, Ukraine, phone +380 577073438 , e-mail: serg_73@i.ua

How to cite this article:

Baranov M.I., Rudakov S.V. Approximate calculation of basic characteristics of plasma at the air electric explosion of metal conductor. Electrical engineering \& electromechanics, 2017, no.6, pp. 60-64. doi: 10.20998/2074272X.2017.6.09. 